\title{
Deixis: A Pragmatic Perspective
}

\author{
${ }^{1}$ Prof. Dr. Fareed Hameed Al-Hindawi, ${ }^{2}$ Lecturer Dr. Mariam D. Saffah \\ ${ }^{1,2}$ Department of English/College of Education/Islamic University Najaf/Iraq
}

\begin{abstract}
It can be said that the relationship between language and context is best manifested through the concept of deixis. It refers to a set of expressions whose interpretation depends on the context in which they appear. The current study tries to present a thorough review of the topic in question from a pragmatic perspective, enhancing its different categories, functions, and shedding some light on its relation to the phenomenon of indexicality. Deixis has not been given its due attention. Thus, this study attempts to bridge this gap in the literature through answering the following questions: What are the categories of deixis? What is the role of context in interpreting deixis? And what is the relation between deixis and indexicality? This survey eventually reveals that deixis has to do with the connection between context and the speaker's communicative intention.
\end{abstract}

Key words: deixis, pragmatics, context, proximal, distal, gestural and symbolic deixis, indexicality

\section{Introduction}

According to Levinson (1983: p. 54), the most noticeable way in which the relation between language and context revealed in the structures of languages themselves is through the phenomenon of deixis. The term is borrowed from Greek word for pointing or indicating.

Some sentences of English are almost impossible to be understood without knowing the context in which they occur. For example: They'll have to do that tomorrow, because they aren't here now. It can be seen that out of context this sentence is extremely vague. This is due to the fact that it includes a large number of deictic expressions (they, that, tomorrow, here, now) whose interpretation depends on the immediate physical context in which they are spoken. These expressions are very obvious instances of bits of language which can only be understood in terms of the speaker's meaning (Yule, 1985: p. 99).

Cruse (2006: p. 44) suggest that deictic terms constitute a subcategory of definite referring expressions. Moreover, usage of the term deixis varies, but most naturally it describes referring expressions which refer to the location of the speaker as a referent point or deictic centre. An example is the use of this and that. In Can you pass that newspaper, the newspaper specified is typically fairly distant from the speaker. Nevertheless, as soon as the speaker obtains the newspaper, another reference to it will involve a different deictic element, I'm going to have to stop buying this newspaper. Such change is a characteristic of a deictic expression.

It is asserted that deixis assumes a principal place in the study of context due to the fact that it represents the solitary most noticeable way in which the speech settings is encoded in language structure itself. Such expressions appear in all human languages and possess a number of fascinating features that set them apart from other interactive resources, verbal and nonverbal. It is assumed that as long as language is basic to 


\section{Dr. Fareed Hameed Al-Hindawi et. al/ Deixis: A Pragmatic Perspective}

human sociality, deixis is basic to language through its capability of constituting both subjects and objects (Hanks, 2005: p. 191).

According to Chapman (2011: p. 40), deixis refers to a category of expressions whose main purpose is to connect uses of language to the context in which they appear. These are ubiquitous in language. In English demonstrative pronouns and adjectives, first and second person pronouns, and some time and place adverbs can be employed via the speaker to point. The postulation is that the speaker and listener share the same context (LoCastro, 2012:p. 24).

\section{Proximal and Distal Deixis}

According to Green (2006: p. 178), deixis is normally considered to be the encoding of the spatiotemporal context and subjective experience of the encoder in an utterance. Terms like I, here, now and this are deeply context-dependent and signify a sort of cognitive centre of positioning for the speaker. That is, what is here for the speaker may be there for the addressee(s).

Prior to that, Yule (1996: p. 9) proposes that the most basic distinction made by deixis seems to be "near the speaker" and "away from the speaker". Hence, there are both proximal terms (this, here, now) and distal terms (that, there, then).

As for deictic elements, it is suggested that a broad distinction can be made between what is closed to or distant from the speaker (Yule, 2017: p. 367). Moreover, proximal terms are normally understood in terms of the speaker's location, i. e. the deictic center. Therefore, now is usually comprehended as referring to some point or period in time that has the time of the speaker's utterance at its center. However, distal terms can mostly indicate "away from speaker's" (Yule, 1996: p. 10).

Nevertheless this is not the case in some languages. For instance, Japanese has a three-part deictic system. So, it is possible to distinguish near the speaker (kore), near the addressee (sore) and away from both (are) (LoCastro, 2012:p. 24).

\section{Categories of Deixis}

As for deixis, a phrase is interpreted with regard to the time, location, or interlocutors of the linguistic exchange in which it occurs, or relative to other linguistic material in that very exchange (Birner, 2013: p. 114).Consequently, five major categories of deixis can be distinguished. They are person, spatial, temporal, discourse and social deixis. Each will be explained below:

\subsection{Person Deixis}

According to Yule (1996: p. 10), person deixis involves a basic three- part division, represented by the pronouns for first person (I), second person (you), and third person (he, she, it). In face-to-face interactions, the persons that $I$ and you refer to are continually altering, as the interactants exchange roles in the course of the talk.

It is stated that with $W e$, the speaker can include the addressee with the speaker explicitly in the activity. That is, We can be inclusive or exclusive, depending on the intended meaning (LoCastro, 2012:p. 24). The difference between inclusive and exclusive we may be noted between (Levinson, 1983: p. 69)

Let's go to the cinema (inclusive)

Let us go to see you tomorrow (exclusive) 


\section{Dr. Fareed Hameed Al-Hindawi et. al/ Deixis: A Pragmatic Perspective}

Birner (2013: p. 116) suggests that in s person deixis a linguistic expression is utilized for the purpose of picking out a particular individual in the context who may not have already been linguistically provoked. The most common instances involve the use of the pronouns $I$ and you.

In many languages, the three deictic categories of speaker, addressee, and other(s) are expanded with markers showing relative social status. That is, expressions which reflect higher status are referred to as honorifics. Additionally, the discussion of the circumstances which cause the selection of one of these forms rather than another is occasionally designated as social deixis (Yule, 1996: p. 10).

From a deictic perspective, third person is not an active participant in basic (I-you) distinction and is inevitably an outsider. That is, third person pronouns are accordingly distal forms in terms of person deixis. Utilizing a third person forms, where a second person form would be appropriate, represents one way to communicate distance and non-familiarity. In English, this is resorted to for ironic or humourous purpose. This occurs in exchanges where one person who is busy in the kitchen, addresses another that is being very lazy: Would his highness like some coffee? (ibid.).

\subsection{Spatial Deixis}

Levinson (1983: p. 79) mentions that spatial or place deixis concerns the specification of locations relative to anchorage points in the speech event. The significance of locational specifications in general is possible to be determined by the fact that there seem to be two basic ways of referring to objects either by describing or naming them or by locating them.

It has been said that the most evident deictic expressions pertaining to spatial deixis are the pair here and there. The language discriminates between them, but context gives them particular meaning. Grounded on what the speaker is talking about, for example, here could be employed to refer to this room, this house, this city or this country (Chapman, 2011: p. 41).

Additionally, spatial deixis appears as part of the meaning of some verbs. For example, come and go are both verbs describing movement. The difference between them is a matter of direction relative to the recent location of the speaker. More specifically, they differ in terms of their relation to the deictic center (ibid.)

Prior to that Palmer (1984: p. 61) proposes that come is restricted more than $g o$ in that it signals direction towards the speaker or hearer. It is used for direction towards speaker or hearer at the time of related event, either in the past or the future, as in He came to me in London, I'll come to see you in Paris. Come is also employed to signal direction to a location at which the speaker or hearer is habitually found, even if he is not there at the time specified, as in Come to my office, I came to your house. However, if the motion is away from the place of the person concerned, go would be more appropriate. Other pair of verbs such as bring and take function in exactly the same way like come and go with the additional meaning of carry.

Yule (1996: p. 12) says that when considering spatial deixis, it is important to keep in mind that location from the speaker's point of view can be fixed both mentally and physically. Hence, speakers momentarily away from their home location will habitually continue to use here to mean the physically distant home location as if they were still in that location. Similarly, speakers appear to be capable of projecting themselves into other locations before actually being in those locations, as when they say I'll come later (movement to addressee's location).

It is suggested that the truly pragmatic basis of spatial deixis is actually psychological distance. Thus, physically near objects tend to be treated by the speaker as psychologically close. Similarly, something that is physically distant is typically treated as psychologically distant (ibid: p. 13). 


\section{Dr. Fareed Hameed Al-Hindawi et. al/ Deixis: A Pragmatic Perspective}

According to (LoCastro, 2012:p. 25), a crucial point regarding spatial deixis is that distance from the speaker or addressee could be psychological and not simply physical. That is, it depends on the speaker's affective stance towards the addressee or situation. For instance, psychological distance can be conveyed via the speaker uttering I don't like that, referring to the behavior of a child standing right in front of the speaker. Here, the speaker employs that to express an attitude of displeasure, even disgust or anger concerning the child's behavior.

Moreover, it is mentioned that deictic expressions relative to the addresses location are less common than those pertain to the speaker location but they are by no means rare. Consider the example:

I thought I just come in and rest a bit before proceeding on my way.

Here, come indicates movement towards the location of the addressee rather than that of the speaker (Birner, 2013: p. 117)

\subsection{Temporal Deixis}

There exists a third category of deixis which signals temporal meanings such as now and then. In this regard, it is said that time deixis resembles all aspects of deixis in making ultimate reference to participant-role. Hence, as a first approximation now can be marked as 'the time at which the speaker's producing the utterance containing now' (Levinson, 1983: p. 73).

According to Yule (1996: p. 14), the use of the proximal now signifies both the time coinciding with the speaker's utterance and the time of the speaker's voice being heard. Contrary to now, the distal expression then applies to both past and future time relative to the speaker's present time, as in:

November $22^{\text {nd }}$, 1963: I was in Scotland then.

Dinner at 8:30 on Saturday? Okay, I'll see you then.

Interpretation of such utterances relies on knowing the utterance time, i. e. when the speaker is doing the talking. For instance, if a teacher leaves a note on her office door that reads, I'll be back in an hour. Gone to the library, students coming to visit the teacher for help cannot know when the hour is up unless they know the time when the message was put on the door (LoCastro, 2012: p. 26).

Similar to spatial deixis, the basis of temporal deixis seems to be psychological. That is, temporal events can be considered as objects moving toward or away from speakers. One metaphor common in English is of events coming toward the speaker from the future, for instance, the coming week, or going away from the speaker to the past, as in the past week. Additionally, near or immediate future seems to be treated as being close to utterance time by employing the proximal deictic this , as in this coming week (Yule, 1996: p. 14).

Contrary to other languages, English has only two basic tense forms, the present and the past. The present represents the proximal form whereas the past refers to the distal one. Something having taken place in the past tends to be treated as distal from the speaker's present situation. Additionally, the distal form is also used for something that is regarded as extremely unlikely from the speaker's present situations (Yule, 1996: p. 15).

LoCastro ( 2012:p. 26) asserts that there exists another type of temporal deixis that stems from present and past verb tenses in English that can signify proximal and distal deictic meanings.

Current moment: I teach in the United States. (now) 


\section{Dr. Fareed Hameed Al-Hindawi et. al/ Deixis: A Pragmatic Perspective}

Distant from the current moment: I lived in Paris (in the 1960s)

Distant from reality: If I could live anywhere in the world..... (but I don't have such choice)

\subsection{Social Deixis}

According to Levinson (1983: p. 89), social deixis pertains to those facets of language structure that embody the social identities of participants, or their social relationships or the relations between one of them and persons and entities denoted. There exist numerous of such aspects of language usage that involve these relations but these are only applicable to the topic in question as long as they are grammaticalized. Examples include polite pronouns and titles of address.

Chapman (2011: p. 42) mentions that terms of address represent instances of social deixis which orient an utterance to the social relationship in its context. There may exist no real difference in the two alternatives in I'm pleased to see you John/Mr Smith, but there are considerable differences in terms of that is proposed concerning social and personal relationships. The array of such terms accessible in English is quite narrow but some languages such as Japanese exhibit much more sophisticated system of terms denoting social standing.

It has been mentioned that a well-known instance of a social disparity is the distinction between forms used for familiar versus non-familiar addressee. This is known as the $\mathbf{T} / \mathbf{V}$ distinction and it occurs in many languages including French, German and Spanish. The selection of one of the two forms will definitely imply something regarding the relationship between the speaker and addressee. Therefore, when interlocutors desire to show distinction between the social status of the speaker and addressee, the higher, older, and more powerful speaker tends to employ the $t u$ version to a lower, younger and less powerful addressee and be addressed by the vous form in return (Yule, 1996: p. 11).

According to LoCastro (2012: p. 26), the fourth category of deixis embraces linguistic resources that encode social status differences, such as the choice between $t u$ and vous in French and $d u$ and Sie in German. It has been noticed that $t u$ is used with friends and intimates in France, whereas in other francophone territories of the world it also conveys solidarity. However, vous is used with all nonfamiliars to demonstrate respect to the person addressed usually because they are older or more important than the speaker.

Hence, the second person plural form vous or the third person plural form Sie has a honorific function. When considering such use of language, Levinson (1983: p. 90) proposes that deictic terms such as these are originated to a referent rather than to an addressee. That is, interlocutors address their equals and refer to their superiors.

It is suggested that social deixis permits the speaker to convey social and other contextual meanings through the choice of one deictic markers. For instance, Japanese avoids the use of personal pronouns in direct address despite their existence. Hence, when they are utilized social and attitudinal meanings are present that has nothing to do with the pointing or deictic function. The example below shows that the speaker has a negative attitude towards the person or her habit of being late (ibid: p. 27).

Kanojo wa, itsumo osoi in desu. (Her, she’s always late!)

\subsection{Discourse Deixis}

Levinson(1983: p. 85) states that discourse deixis concentrates on the use of expressions within a specific utterance to refer to some portion of the discourse that encompasses that utterance. In this category, it is 
possible to include a number of other ways in which an utterance signifies its relation to a surrounding text. For instance, utterance-initial anyway seems to denote that the utterance includes it is addressed to one or more steps back rather than the immediately prior discourse.

It is assumed that this category is the least common of the fourth categories of deixis and is not universally. In discourse deixis, the deictic expression is utilized not in reference to a part of context or utterance, but rather to a part of the utterance itself or a proposition evoked by that same utterance, as in: I bet you haven't heard this story / That was the funniest story I've ever heard (Birner, 2013: p.119) .

Levinson (1983: p. 85) claims that a clear distinction between discourse deixis and anaphora should be drawn otherwise considerable confusion may arise. Anaphora concerns the use of a pronoun to refer to the same referent as some prior term. For instance, in Harry's a sweetheart; he's so considerate, harry and he are said to be co-referential. Additionally, anaphora can hold within sentences, across sentences, and across turns at speaking in a dialogue.

Nevertheless, deictic or other definite referring expressions are often employed to introduce a referent, whereas anaphora pronouns are used to refer to the same entity afterwards. In other words, when a pronoun refers to a linguistic expression itself, it is a discourse-deictic, while it is anaphoric where it refers to the same entity as a previous linguistic expression does. In the example below, it refers not to the referent, the beast itself, but to the word rhinoceros. That is, it is not doing a duty for the use of rhinoceros but rather for a mention of it (ibid: p. 86).

\section{A: That's a rhinoceros \\ B: Spell it for me}

As for the difference between anaphora and deixis, Green (2006: p. 178) assumes that it is quite straightforward in standard accounts but a growing pragmatic highlighting has rendered the distinction less easy to capture. In the former, anaphora is viewed as much more of an intralinguistic or intrasentential element. For instance, in That man is very tall. He must have trouble buying clothes, the deictic expression that man should be assigned pragmatic interpretation. However, the pronoun he is said to refer back to the foregoing element.

According to LoCastro (2012: p. 27), all languages can be considered as referential in nature and referring expressions, such as deictic markers are not the only means available to specify connections between a speaker's talk and the surrounding world. Common anaphoric expressions in English include proper nouns, definite and indefinite noun phrases and pronouns. The selection of a referring expression depends on the speaker's assumptions as to how much information the addressee requires to understand the speaker's utterance.

\section{Gestural and Symbolic Deixis}

Levinson (1983: p. 65) states that some deixis requires for their interpretation a reference to an audio-visualtactile monitoring of the speech event. These are referred to as gestural deixis. Examples include demonstrative pronouns utilized with a selecting gesture, or second or third pronouns used with some physical indication of the referent, as in:

This one's genuine, but this one is a fake.

$H e$ 's not the Duke, he is. He's the butler. 


\section{Dr. Fareed Hameed Al-Hindawi et. al/ Deixis: A Pragmatic Perspective}

However, symbolic deixis demands merely knowledge of the basic spatio-temporal parameters of the speech event for their interpretation. Hence, it suffices to know the general location of the participants to interpret, This city is really beautiful (ibid.).

Similarly, Cruse (2000: p. 325) mentions that continuous monitoring of the speech situation is not necessary to make sense of symbolic deixis. That is, the relevant parameters for the deictic interpretation are established over long periods of a conversation or discourse, as in:

I've lived in this town for twenty years.

Those foreigners are always whining

As for the difference between the two uses specified, it is suggested that it is one of degree. Nevertheless, there exists a substantial consequence of that distinction in that it is merely in the case of gestural deictic terms the place denoted by here need not contain the position of the speaker, as in: Will you please sign here, sir?(ibid: p. 326).

\section{Deixis and Grammar}

According to Yule (1996: p. 15), the distinctions outlined previously concerning person, spatial and time deixis seem to be in accordance with the distinctions made between direct and indirect speech. Hence, the deictic expressions for person, place, and time can also be interpreted within the same context as the speaker who utters (a) below

a. Are you planning to be here this evening?

b. I asked her if she was planning to be there that evening.

When the context shifts to one of reported speech, the prior utterance is marked deictically as relative to the circumstances of asking. It can be observed that the proximal forms presented in direct speech have shifted to the corresponding distal forms in the reported version. Additionally, the proximal deictic forms of a direct speech reporting convey a sense of being in the same context as the utterance. However, the distal deictic forms of indirect speech reporting cause the original speech event seems more distant (ibid: p. 16).

Finally, Chapman (2011: p. 42) states deixis seems to provide an example of a linguistic phenomenon where no solitary label can account for it appropriately in that it blends grammatical facets with pragmatic ones.

\section{Deictic Change}

As known, modern English has dispensed with the familiar second person thou while location-signifying forms such as hence and yonder are now archaic. Besides, some of the deictic terms which are no longer utilized in face-to-face communication have attain a place in the interaction that goes between a writer and reader. For instance, hence and thence are often employed to guide a reader up and down a text to the current place in the discourse in relation to a deictic centre. When considering deictic change, it is assumed that the prevailing of literacy and the use of writing in nowadays interaction signals that redundant face-toface interaction deixis such as hence assumes a new role in written interactive discourse (Grundy, 2000: $p$. 36).

\section{Deixis and Indexicality}

According to Grundy (2000: p. 23), the property of language studied so far is called indexicality while the lexical items which encode context in this way are termed as deixis. 


\section{Dr. Fareed Hameed Al-Hindawi et. al/ Deixis: A Pragmatic Perspective}

Levinson (1983: p. 57) says that there exists a substantial philosophical interests in expressions that exhibit context-dependence property such as demonstratives, first and second person pronouns, and morphemes denoting tense. It is mentioned that it is Peirce who first terms such expressions indexical signs, and claims that they involve a reference by an existential relation between sign and referent. His category actually contains more than the directly context-dependent expressions that are nowadays called deictic or indexical, and his specific system of categories has not been given much attention in linguistic pragmatics.

According to LoCastro (2012: p. 23), there exist referential expressions whose function is to designate association between context and the speaker's communicative intention in all languages. These are named indexicals. Thus, indexicality is a linguistic phenomenon that refers to the potential meanings covertly attached to a certain word. For example, I am here now assigned a different contextual meaning in each situation where it is employed. If a friend phones from Grand Central Station in New York City, with the message I am here now, both the caller and the listener on the telephone line should have previously decided on what here and now mean otherwise they may not be able to find each other in the large train station.

It can be said that indexicals represent typical signs to make reference between interlocutors. They are essential for accounting for the indeterminacy of linguistic forms with no clear meaning outside of an instance of use. For example, when one son returns home without the other son, their mother might ask Where's Tony? She may get the answer, He fell down. Here, the indeterminacy of the words makes the her allocate sense and reference to the utterance. In such context, words such as he and fell down are indexed, i.e. their meaning is determined via comparing them to elements found in the local situation (ibid.).

In a more recent account, Williams (2019: p. 3) states that deixis constitutes a subtype of indexicality which signifies a linguistic anthropological understanding that is grounded on the semiotic theory of Charles Sanders Peirce. Within this framework, indexicality performs a semiotic function through which a signifier points to an object or entity by means of spatio-temporal continguity. This indexical function is distinguished from two other ones, symbolic and iconic. While the former is characterized via a random relationship, the latter is marked by that of resemblance.

Two types of indexicality has been distinguished by scholars: referential and nonreferential. Whereas referential indexicality contributes to the semantic-referential meaning of an utterance, nonreferential indexicality typically does not even though social deixis seems to absorb the line between the two. Examples of the latter include regional accents, practices indexing speaker's sex, honorifics, and speech acts (ibid.).

Successive work on indexicality in linguistic anthropology has concentrated on the intricate connections between linguistic and other semiotic practices and socially assembled identities. Deixis has simultaneously been investigated more thoroughly by linguists interested in the more referential aspects of language. Hence, descriptive linguistics devotes considerable attention to deixis stressing its universality across languages (ibid.).

\section{Concluding Remarks}

1. It can be said that deixis is a common instance of everyday language designating a set of expressions that depend on the context in which they appear for their interpretation. Hence, they clearly fall within the realm of pragmatics.

2. Five distinct categories of deixis have been distinguished. However, it is proposed that some categories, namely person, spatial and temporal deixis are characterized as the major categories while social and 
discourse deixis represent the marginal ones. This is based on the occurrence of deictic elements in spoken interactions.

3. Numerous languages have a three-part system of forms for personal pronouns. Thus, English has first person $I$, second person you, and third person he, she, it which refer to the speaker, addressee and others external to the immediate context. Additionally, first person we can be inclusive or exclusive dependent on the intended meaning.

4. When a speaker wishes to show the relative social status of the addressee, he resorts to what are referred to as honorifics such as the choice between tu and vous forms which occurs in some European languages such as French. The former is utilized with friends and familiars while the latter is employed to demonstrate respect for an unfamiliar addressee who is considered to be superior to the speaker. Such deictic markers fall within the category of social deixis.

5. As for discourse deixis, a distinction can be made between these deictic terms and anaphoric pronouns. It is suggested that the former are often used to introduce a referent, while anaphora pronouns are used to refer to the same entity afterwards.

6. Moreover, indexicality refers to a linguistic phenomenon designating the potential meaning indirectly attached to a word. This is realized by means of a set of expressions whose function is to handle the indeterminacy of linguistic forms whose meaning depends on the context in which they occur. These are called indexicals. They concentrate on the association between context and the communicative intention of speakers.

Lecturer Dr. Mariam D. Saffah holds an M.A. in Pragmatics from Babylon University, and a Ph.D. in English Language and Linguistics from Babylon University. She is also interested in Pragmatics, Phonetics and Phonology and Discourse analysis. She published 2 books and 8 research papers

ORCID: https://orcid.org/0000-0002-1277-4623

Prof. Dr. Fareed H. Alhindawi is a professor of linguistics in the College of Education for Human Sciences/University of Babylon. He majors in applied pragmatics. He published more than 60 research papers and authored, coauthored, and edited more than 12 books in different fields of linguistics.

\section{References}

1. Birner, Betty J. (2013). Introduction to Pragmatics. West Sussex: John Wiley and Sons Ltd.

2. Chapman, S. (2011). Pragmatics. London: Palgrave Macmillan.

3. Cruse, Alan. (2000) Meaning in Language. Oxford: Oxford University Press.

4. Cruse, Alan. (2006). A Glossary of Semantics and Pragmatics. Edinburgh: Edinburgh

5. University Press.

6. Green, K. (2006). Deixis and Anaphora: Pragmatic Approaches. In Mey, J. (Ed.) Concise Encyclopedia of Pragmatics. Hank, W. F. (2005). Explorations in the Deictic Field. Current Anthropology, Vol.46 (2): 191: 220. Amsterdam: Elsevier.

7. Grundy, P. (2000). Doing Pragmatics. London: Arnold.

8. Levinson, S. (1983). Pragmatics. Cambridge: Cambridge University Press.

9. LoCastro, V. (2012). Pragmatics for Language Educators. London: Routledge.

10. Palmer, F. (1984) Semantics. Cambridge: Cambridge University Press.

11. Yule, G. (1996). Pragmatics. Oxford: Oxford University Press.

12. Yule, G. (1985: The Study of Language. Cambridge: Cambridge University Press

13. Yule, G. (2017) The Study of Language. Cambridge: Cambridge University Press.

14. Williams, N. (2019). Deixis; Deixis and Indexicals. University of Colorado Boulder. 